\title{
Study on Temporal and Spatial Evolution of Placenames Named in Yi Nationality Language in Guizhou Province
}

\author{
Wujun Xi \\ School of Geography and Tourism Management \\ Chuxiong Normal University \\ Chuxiong, China
}

\begin{abstract}
The aim of this study was to find the temporal and spatial evolution situation of placenames named in Yi nationality language in Guizhou province. Distribution direction and average center indexes were used to indicate temporal and spatial evolution situation. The results showed that the spatial distribution direction could be roughly regarded as northeastsouthwest direction, and its average central coordinate was located in Nayong County. The average center trajectory of these placenames first moved to southeast direction and then moved to northwest direction. These results had reference value for studying the activity range and migration of the Yi people.
\end{abstract}

Keywords-Placenames named in Yi Nationality Language; Temporal and spatial evolution; Guizhou

\section{INTRODUCTION}

The YI nationality people in the long-term production and life produced many placenames named in YI nationality language. Referring to Wang Guanxiong's research [1], Placenames named in YI nationality language, named after the placenames which reflects the YI nationality's naming way of thinking and the YI nationality cultural connotation. It is also the YI nationality people identity and naming the geographic entities in language code [2]. At present, domestic research on placenames named in YI nationality language mainly focuses on linguistics [3-8], its relationship with natural social environmental factors [9-13], naming[2,14], connotation [15],significance [16],etc. The spatio-temporal analysis of placenames named in YI nationality language only found the case study of Yunnan Province [17]. In order to attain the spatio-temporal evolution situation of Guizhou placenames named in YI nationality language, the distribution direction and the average central index were used in this paper.

\section{SOURCES AND IDENTIFICATION OF PLACENAMES NAMED IN YI NATIONALITY LANGUAGE IN GUIZHOU PROVINCE}

The placenames named in YI nationality language comes from the "gazetteer of the People's Republic of China Guizhou Province"[18], it contains 3,805 placenames, 178 placenames named in YI nationality language were found by screening, the proportion is $4.68 \%$. The identification of placenames named in YI nationality language is the same as that in Yunnan Province case study [17].

\section{THE TIME DISTRIBUTION OF PLACENAMES NAMED IN Y NATIONALITY IN GUIZHOU}

There are 53 placenames that have time recording among 178 placenames named in YI nationality in Guizhou, the proportion is only $29.76 \%$. The placenames that have time recording include the Warring States, the Yuan Dynasty, the Ming Dynasty, the Qing Dynasty and the Republic of China. The farther the time is from now, the more discontinuous the record, the less the number of placenames. There was only 1 placename named in YI nationality in the Warring States period, after the middle of the blank period, there are 3 placenames in Yuan Dynasty, 30 placenames in the Ming Dynasty, 14 placenames in the Qing Dynasty, and 5 placenames in the Republic of China. Overall, the Ming Dynasty and the Qing Dynasty are clearly concentrated. This should be related to the activities and strength of the Yi people, but it also was related to time, after all, records that are too old are hard to reserved.

\section{ANALYSIS OF THE SPATIAL AND TEMPORAL EVOLUTION OF PLACENAMES NAMED IN YI NATIONALITY LANGUAGE IN GUIZHOU}

6 of the 53 placenames named in YI nationality language with time recording did not find their coordinates, they are Pingshang, Zhuhua, Xiamuyi, Cheniba, Ciwazhai, and Fayu. The spatial distribution of the remaining 47 placenames was shown in Figure 1.The blue dots indicate the placenames with time record, dark red dots indicate placenames that have no time record. It can be seen that the placenames with time recording are scattered everywhere, and don' $t$ present a concentration situation, and they are consistent with those that have no time record. 


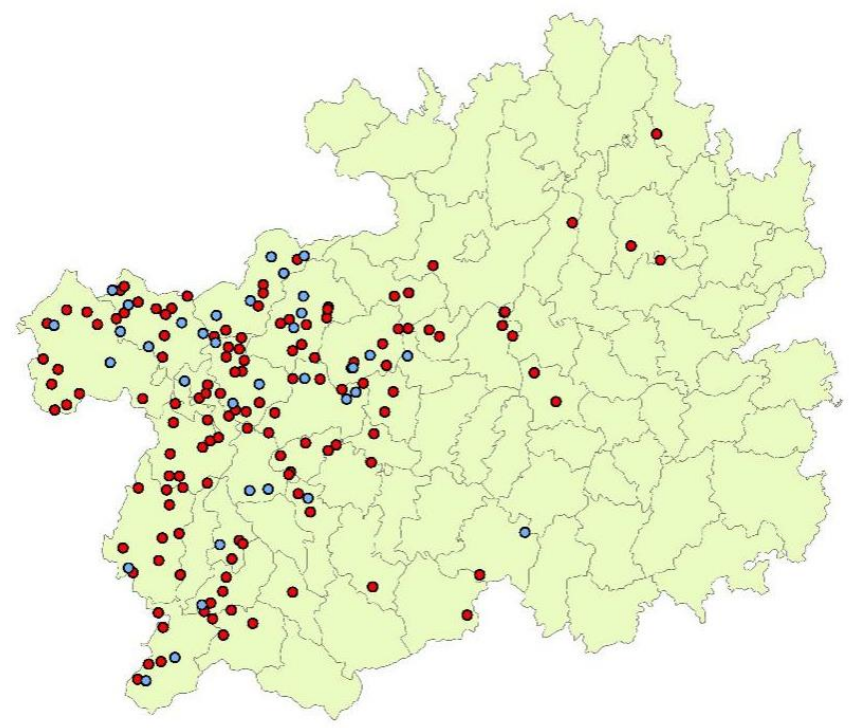

Fig. 1 Spatial distribution of placenames named in YI nationality language with time record in Guizhou

In order to measure its overall distribution, the distribution direction and average center indexes were used, the result was shown in Figure 2. Among them, the blue dot indicates the average center of the placenames with time record.

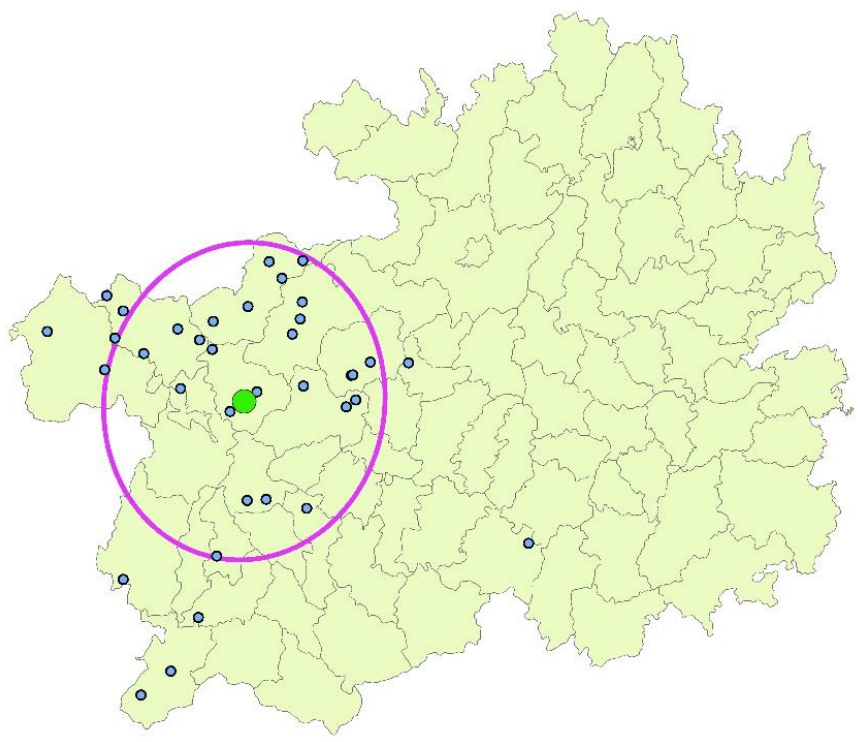

Fig. 2 Spatial distribution direction and average center of placenames named in YI nationality language with time recording in Guizhou

First of all, the spatial distribution direction could be roughly regarded as northeast-southwest direction, and the ellipse long axis angle was $38.59^{\circ}$.Secondly, its average central coordinates was $105^{\circ} 17^{\prime} 19.968^{\prime \prime E}, 26^{\circ} 42^{\prime} 45.2736^{\prime N}$.It was located in Nayong County of Bijie.

In order to explore the spatial distribution and evolution of the placenames in different dynasties, they were decomposed to figures 3-6.

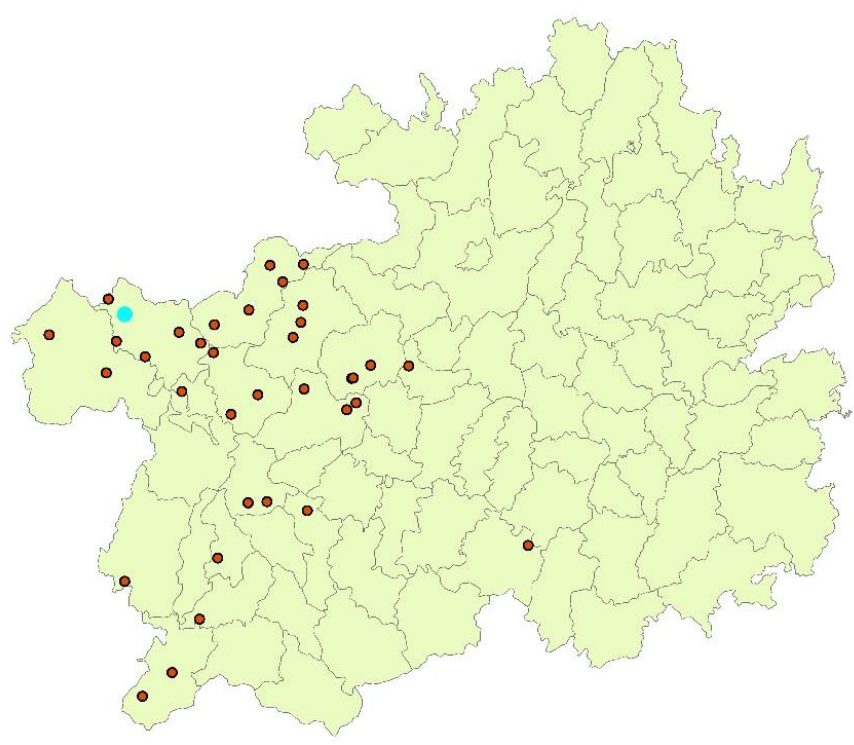

Fig. 3 Placenames named in YI nationality language in the Warring States Period

The blue dot indicated the placename in the Warring States period, and the dark red dots indicated placenames of the other dynasties (the same below).It could be seen that the placename in the Warring States period was located in Hezhang county.

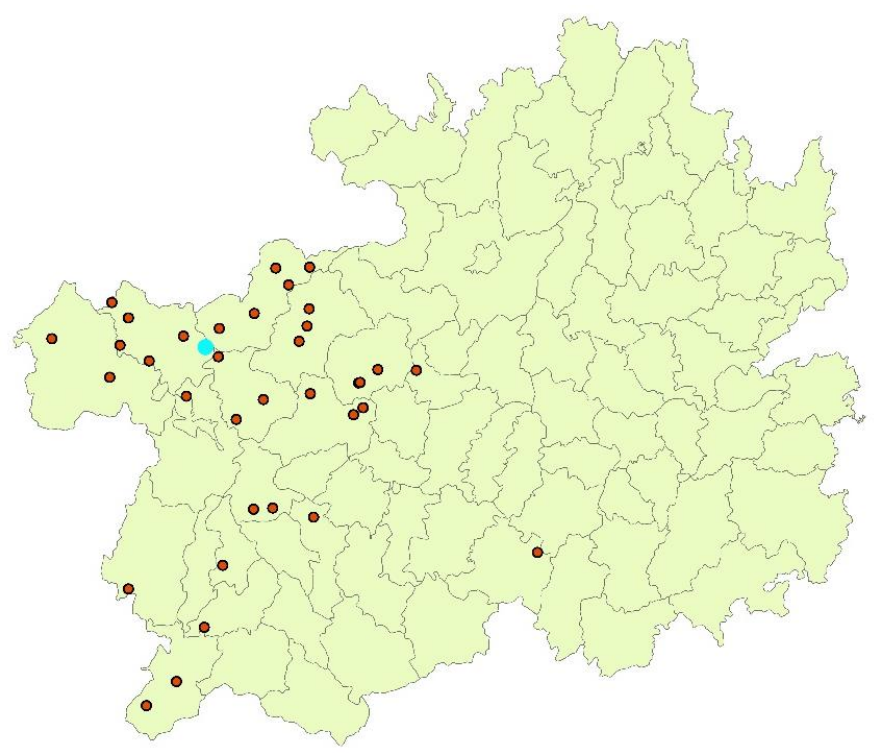

Fig. 4 Placenames named in YI nationality language in Yuan Dynasty

It could be seen that the placename in the Yuan Dynasty was located in Hezhang county also from figure 4. 


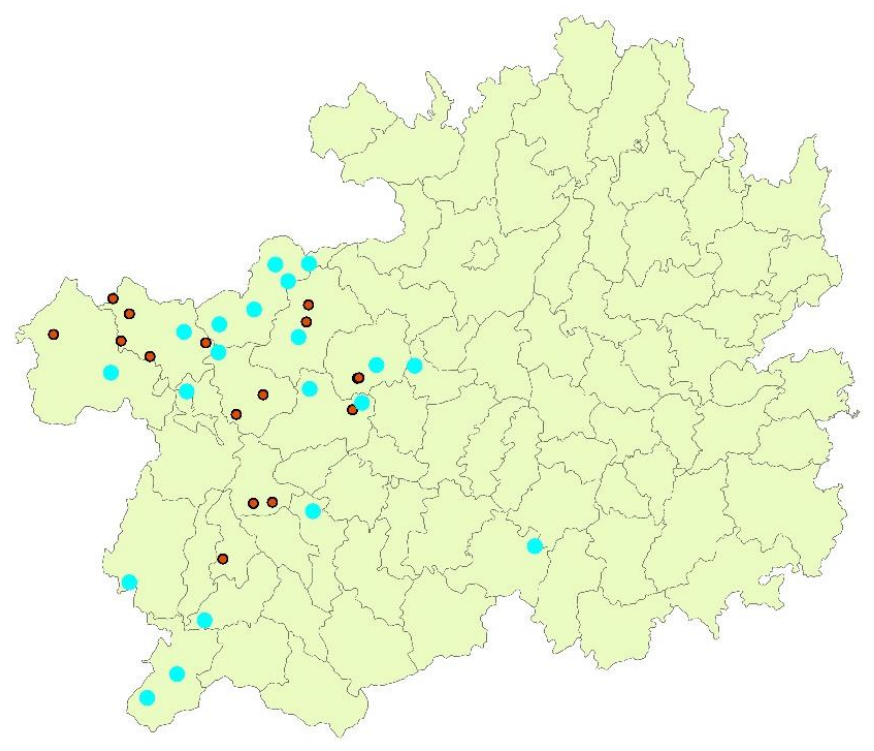

Fig. 5 Placenames named in YI nationality language in Ming Dynasty

It can be seen from figure 5 that placenames of the Ming Dynasty were distributed in Hezhang county, Bijie city, Dafang county, Weining county, Shuicheng county, Nayong county, Zhijin county, Zhenning county, Qianxi county, Xiuwen county, Pan county, Xingren county, Xingyi city, Pingtang county.

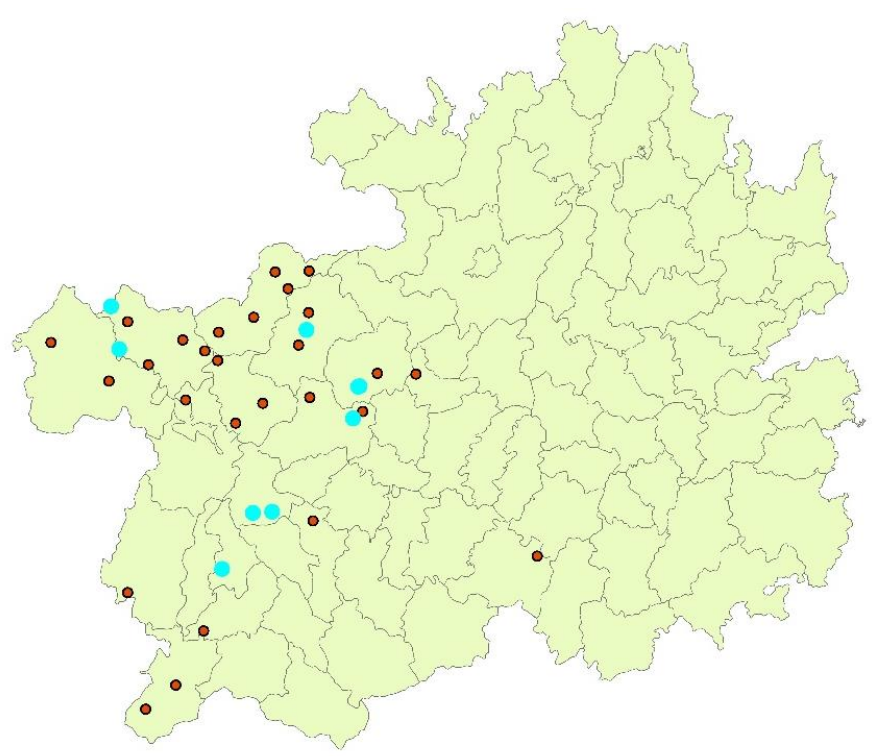

Fig. 6 Placenames named in YI nationality language in Qing Dynasty

It can be seen from figure 6 that placenames of the Qing Dynasty were distributed in Hezhang county, Dafang county, Qianxi county, Zhijin county, Liuzhi special zone, Qinglong county.

In order to further analyze the evolutionary trajectory of placenames named in YI nationality language of different dynasties, the average centers of the dynasties were calculated, and they were shown as table 1 and figure 7 .

TABLE I MEAN CENTER COORDINATE OF PLACENAMES NAMED IN YI NATIONALITY LANGUAGE OF DIFFERENT DYNASTIES IN GUIZHOU

\begin{tabular}{|c|c|c|}
\hline dynasty & longitude & latitude \\
\hline Warring States & $104^{\circ} 23^{\prime} 57.192^{\prime \prime}$ & $27^{\circ} 14^{\prime} 23.388^{\prime \prime}$ \\
\hline Yuan Dynasty & $104^{\circ} 57^{\prime} 2.916^{\prime \prime}$ & $27^{\circ} 5^{\prime} 0.240^{\prime \prime}$ \\
\hline Ming Dynasty & $105^{\circ} 24^{\prime} 6.941^{\prime \prime}$ & $26^{\circ} 37^{\prime} 13.051^{\prime \prime}$ \\
\hline Qing Dynasty & $105^{\circ} 22^{\prime} 17.980^{\prime \prime}$ & $26^{\circ} 40^{\prime} 35.400^{\prime \prime}$ \\
\hline the Republic of China & $104^{\circ} 55^{\prime} 59.632^{\prime \prime}$ & $26^{\circ} 58^{\prime} 1.330^{\prime \prime}$ \\
\hline
\end{tabular}




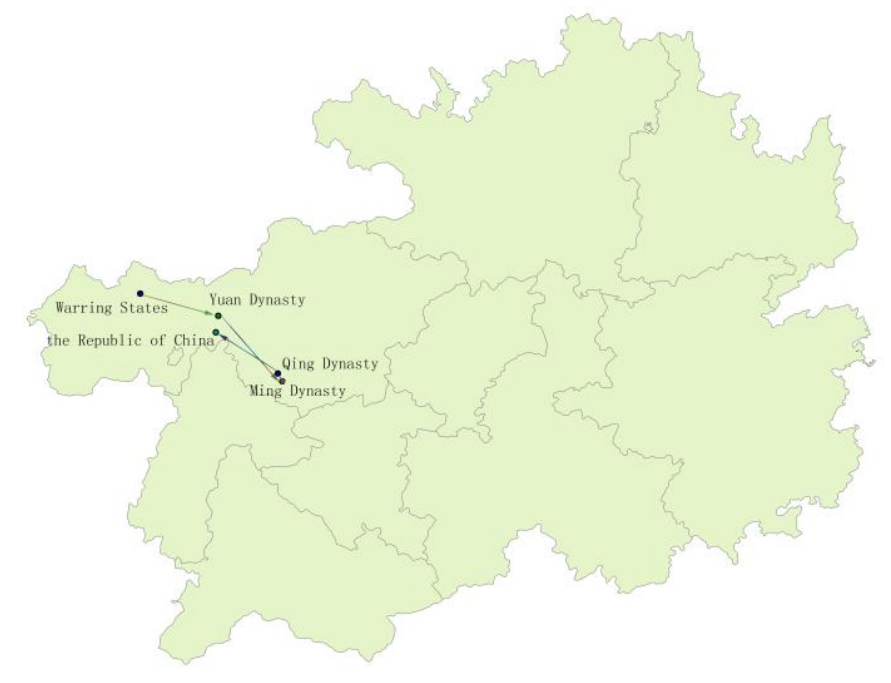

Fig. 7 The trajectory of the average center evolution of placenames named in YI nationality language in Guizhou in different dynasties

It can be seen from figure 7 that the average center trajectory of placenames named in YI nationality language in Guizhou began from the Warring States period, then moved to the southeast direction to the Yuan Dynasty. The Yuan Dynasty continued to move to the southeast direction to the Ming Dynasty, and moved toward the northwest toward the Qing Dynasty. The Qing Dynasty moved to northwest to the Republic of China. Among them, the average centers of the Ming and Qing dynasties were relatively close.

\section{CONCLUSION}

The spatial distribution direction of placenames named in YI nationality with time record in Guizhou could be roughly regarded as northeast-southwest direction,its average central coordinates was located in Nayong County.

The average center trajectory of placenames named in YI nationality language in Guizhou began from the Warring States period, then moved to the southeast direction to the Yuan Dynasty. The Yuan Dynasty continued to move to the southeast direction to the Ming Dynasty, and moved toward the northwest toward the Qing Dynasty. The Qing Dynasty moved to northwest to the Republic of China. Among them, the average centers of the Ming and Qing dynasties were relatively close.

\section{REFERENCES}

[1] Wang Guanxiong. Using GIS to Study the Spatial Distribution and Historical Changes of Zhuang Toponomy in Guangxi.Beijing : Capital Normal University.2009. (In Chinese)

[2] Xi Wujun, Liu Zuxin. Analysis of the Naming Methods of Placenames Named in Yi Nationality Language in Yunnan Province. Chuxiong National Culture Forum. Eighth series. Kunming: Yunnan University Press. 2015. (In Chinese)

[3] Li Tianyuan. Research on the language places in Chinese Characters. Journal of Guizhou University For Nationalities. vol. 2, pp. 84-86, 2003. (In Chinese)

[4] LUO Jiangwen; LUO Yaxin. The Cultural Linguistically Decipherment of Eshan' s Location Name in Yi Language. Journal of Yunnan Agricultural University(Social Science). vol. 8, pp. 88-96, 2014. (In Chinese)

[5] WANG Zhaochun. Discussion on placenames Named in Yi Nationality Language in Bijie dialect. Guizhou Ethnic Studies. vol. 3, pp. 90-93, 2010. (In Chinese)

[6] Bamo Ayi. Placenames Named in Yi Nationality Language in Liangshan.Ethno-national Studies. vol. 6, pp. 51-58, 1987. (In Chinese)

[7] Jin cheng, Wang Chengping. Study On Mianning's Geographical Names ve33le33. Journal Of Sichuan University for Nationalities, vol. 19, pp. 26-28, April 2010. (In Chinese)

[8] Li Shengfu. Analysis of "Xue E Feeding A Myna" in Yi People' s Language: A Study of the Ancient Place Name "Deping. Journal of Guizhou University For Nationalities. vol. 3, pp. 105-107, 2004. (In Chinese)

[9] Xi Wujun. Study on Relationship between Natural and Social Factors and Placenames Named in Yi Nationality Language in Yunnan Province. Geographical Science Research.vol. 5, pp. 105-123, 2016. (In Chinese)

[10] Li Tianyuan. Place Names in Yi Language and Their Ecological Environments in Guizhou Province. National language. vol. 1, pp. 25-28, 2002. (In Chinese)

[11] YANG Tingshuo,LI Tianyuan. On the Compound Lifestyle of Crop Cultivation and Animal Husbandry Embodied in the Geographical Names of the Yi Language. Journal of Jishou University(Social Science) vol. 22, pp. 63-67, 2001. (In Chinese)

[12] Pu Zhongliang. The Ethnic Yi' s Self- appellation and the Names of Places among the Yi Clans. Guizhou Ethnic Studies. vol. 23, pp. 159165, 2003. (In Chinese)

[13] LUO Jiang-wen. Contact and Influence of National Languages and Cultures by Studying the Place Names Transformation between Yi and Han in Eshan. Academic Exploration. vol. 2, pp. 124-130, 2014. (In Chinese)

[14] Sha-ma dage. Denominative patterns and cultural connotation of Place names of Yi language in Liangshan.Journal of Xichang College Social Science Edition. vol. 17, pp. 69-71, 2005. (In Chinese)

[15] Pu Zhongliang. The place names constituted by Yi language ndhe21 and their cultural connotations. National language.vol. 6, pp. 42-48, 1998. (In Chinese)

[16] Wu Guangfan. A Probe into the Toponymy Yi language. Social Sciences In Yunnan.vol. 6, pp. 1-12, 2000. (In Chinese)

[17] Xi Wujun. Spatial Distribution and Evolution of PlaceNames Named in Yi Nationality Language in Yunnan. Kunming: Yunnan People's Publishing House. 2016. (In Chinese)

[18] Chai Xingyi. gazetteer of the People's Republic of China - Guizhou Province. Beijing: The Commercial Press. 1994. (In Chinese) 